\title{
A Comparison of COVID-19 Stigma and AIDS Stigma During the COVID-19 Pandemic: A Cross-Sectional Study in China
}

\author{
Manyun Li ${ }^{1}$, Jiang Long ${ }^{2}$, Xuyi Wang ${ }^{1}$, Yanhui Liao ${ }^{3}$, Yueheng Liu ${ }^{1}$, Yuzhu Hao ${ }^{1}$, \\ Qiuxia Wu ${ }^{1}$, Yanan Zhou ${ }^{4}$, Yingying Wang ${ }^{1}$, Yunfei Wang ${ }^{1}$, Qianjin Wang ${ }^{1}$, Yuejiao Ma ${ }^{1}$, \\ Shubao Chen ${ }^{1 *}$ and Tieqiao Liu ${ }^{1 *}$
}

${ }^{1}$ Department of Psychiatry, and National Clinical Research Center for Mental Disorders, The Second Xiangya Hospital of Central South University, Changsha, China, ${ }^{2}$ Shanghai Mental Health Center, Shanghai Jiao Tong University School of Medicine, Shanghai, China, ${ }^{3}$ Department of Psychiatry, Sir Run Run Shaw Hospital, School of Medicine, Zhejiang University, Hangzhou, China, ${ }^{4}$ Department of Psychiatry, Hunan Brain Hospital (Hunan Second People's Hospital), Changsha, China

\section{OPEN ACCESS}

Edited by: Daria Smirnova,

Samara State Medical University, Russia

Reviewed by:

Levent Kuey,

Istanbul Bilgi University, Turkey Juan Moisés De La Serna, Universidad Internacional de La

Rioja, Spain

*Correspondence: Tieqiao Liu

liutieqiao123@csu.edu.cn Shubao Chen

chenshubao@csu.edu.cn

Specialty section: This article was submitted to

Public Mental Health, a section of the journal

Frontiers in Psychiatry

Received: 24 September 2021 Accepted: 02 November 2021 Published: 01 December 2021

Citation:

Li M, Long J, Wang X, Liao Y, Liu Y, Hao Y, Wu Q, Zhou Y, Wang Y, Wang $Y$, Wang $Q$, Ma $Y$, Chen $S$ and Liu T (2021) A Comparison of COVID-19 Stigma and AIDS Stigma

During the COVID-19 Pandemic: A Cross-Sectional Study in China. Front. Psychiatry 12:782501. doi: 10.3389/fpsyt.2021.782501
Objective: To understand the current situation of stigmatizing attitudes toward Coronavirus Disease 2019 (COVID-19) in China and compare it with acquired immunodeficiency syndrome (AIDS).

Methods: Convenient sampling and vignette-based methods were used to recruit participants on WeChat. A demographic form and adopted stigma scale were used to collect participants' demographic information and stigmatizing attitudes toward COVID-19 and AIDS.

Results: A total of 13,994 questionnaires were included in this study. A high portion of participants tend to avoid contact with individuals affected with COVID-19 (74.3\%) or AIDS (59.0\%), as well as their family members (70.4\% for COVID-19 and $47.9 \%$ for AIDS). About half of the participants agreed that affected persons could not only cause problems to their own family but also have adverse effects on others (59.6\% and $55.6 \%$ for COVID-19, 56.9 and $47.0 \%$ for AIDS). The agreements with statements about perceived stigma were similar but slightly higher than those about personal stigma in both COVID-19 and AIDS. Participants' agreements with all statements regarding personal and perceived stigma attitudes between COVID-19 and AIDS were all statistically significant $(p<0.001)$. Participants obtained COVID-19-related information mainly from social media (91.3\%) and newspaper or television (77.1\%) during the epidemic, and $61.0 \%$ of them thought information from newspapers or television was the most reliable.

Conclusion: Several similarities and differences of people's attitude toward COVID-19 and AIDS were found. Avoidance, blame, and secondary discrimination to diagnosed persons and their surrounding persons were the main representations of COVID-19-related stigma. Stigma of COVID-19 had less moral link but more public panic. Experience from HIV-related stigma reduction and prevention can be applied to reduce COVID-19-related stigma.

Keywords: COVID-19, AIDS, stigma, physical avoidance, public panic 


\section{INTRODUCTION}

Novel Coronavirus Disease 2019 (COVID-19) is an infectious disease caused by severe acute respiratory syndrome coronavirus 2 (SARS-COV-2). The disease spectrum caused by this virus ranges from asymptomatic, fever, cough, and fatigue to severe acute respiratory distress syndrome (ARDS), and even death (1). According to a report of 72,314 cases in China, $81 \%$ patients' symptom was sorted as mild, $14 \%$ were severe that need ventilation in an intensive care unit (ICU), and 5\% were critical that had respiratory failure, septic shock, and/or multiple-organ dysfunction or failure (2). SARS-COV-2 spreads mainly via respiratory and closed contact (3) and is infectious during the latent period (4) which ranges from 2 to 14 days (median: 4-5 days) (5). As the strong infectivity (median $R_{0}=5.7,95 \%$ CI: 3.8-8.9) and fast transmission of SARSCOV-2 (6), COVID-19 soon spread around the world. The WHO proclaimed COVID-19 as a public health emergency and designated it a pandemic on March 11, 2020 (7). There are several vaccines available for COVID-19 which could provide protection for those older than 16 to some extent (8). However, some variations of SARS-COV-2 have been detected globally and the efficacy of vaccines has absolute marked differences $(9,10)$.

Stigma was first proposed by Erving Goffman in 1963, which was defined as a "sign" or an attribute that reduces an individual's status in the eyes of society (11). It was also interpreted as a mark of shame and disapproval that result in a person apart from others (12). It refers to people's negative emotional experience of disease, including personal stigma and perceived stigma. Personal stigma is a process of stereotype, prejudice, and discrimination, while perceived stigma indicates that someone is approved of the public discrimination against the group (13). Extreme fear of a disease and self-defense may be related to stigma. Mental disorders, physical disability, and emerging infectious diseases have been reported with different degrees of stigma (14). Stigma has always been a major focus throughout the pandemic of an infectious disease (3). The impact of infectious disease stigma is no less than the disease itself. Not only does it influence the patients' quality of life and social ability, but it also affects the publics' attitude toward disease prevention, service delivery, medical resource allocation, and health policymaking (15). Isolation measures were taken during the outbreak of COVID-19, which effectively decreased the morbidity and mortality of COVID-19 but may increase stigma inversely (16). Some scholars pointed that compared with other regions, people resident in the infectious area were more likely to be prejudiced and discriminated (17). The fear of getting infected of COVID-19 and self-defense might contribute to stigmatizing attitude (18), and the stigma of this infectious disease may inversely lead to delayed help-seeking. COVID-19related stigma may pose a serious threat to COVID-19 patients and survivors, as well as their families and surrounding people. Several incidents of stigmatization, even physical violence toward patients, survivors, and medical workers, have occurred during this pandemic all around the world (19). There were numerous studies investigating sleeping disorder, anxiety, depression, posttraumatic stress disorder, and other mental disorders related since the outbreak of COVID-19; however, few have focused on COVID-19-related stigma (20). Since there is no effective therapy toward COVID-19 so far, people's attitude to COVID-19 is worth investigating.

Acquired immunodeficiency syndrome (AIDS), caused by human immunodeficiency virus (HIV), is another kind of infectious disease transmitted mainly via unprotected sexual activity, contaminated blood transfusion, and contaminated needles and from mother to child during pregnancy (21). Numerous studies about AIDS and its stigma have been done (22), and several systematic reviews have been published $(23,24)$. Previous stigma-related studies on AIDS reported that HIV-positive individuals were more vulnerable to receive stigma from others, which usually contain health, moral, and racial dimensions and promoted stigma including intrapersonal, interpersonal, and social aspects (25). Both COVID-19 and AIDS are infectious diseases with no definite therapy, and suffering from COVID-19 or AIDS will cause a certain damage to both individuals and our society. Therefore, we try to learn COVID-19 stigma by comparing with AIDS stigma, as Logie thought that we can learn the experience of studying AIDS stigma and leverage the approaches used to reduce AIDS stigma to address COVID-19 stigma (26).

Hence, we conducted this study with the aims of (1) investigating publics' stigmatizing attitudes toward COVID19 and (2) comparing publics' stigmatizing attitudes between COVID-19 and AIDS to find the similarities and differences. From this study, we hope to provide some theoretical basis for psychological intervention toward COVID-19 stigma and further policymaking.

\section{MATERIALS AND METHODS}

\section{Participants}

Participants were recruited online, and inclusion criteria were (1) age $\geq 16$, (2) can fully understand the informed consent and questionnaire, (3) willing to participate in the survey and can sign the informed consent online.

\section{Procedures and Materials}

Data were obtained using the convenient sampling method through a WeChat-based questionnaire including demographic questionnaire, a stigma scale that was adopted from the Explanatory Model Interview Catalog-Community Stigma Scale (EMIC-CSS) (27), and Depression Stigma Scale (DSS) (28). Participants' demographic information such as gender, age, education, and occupation was collected through a demographic questionnaire. The 18-item stigma-related scale consists of personal stigma aspect and perceived stigma aspect with nine items separately (seen in Supplementary Table S1) and was used to measure participants' stigma attitudes toward COVID-19 and AIDS. A vignette-based survey method was used in this study. A hypothetical case diagnosed with 
COVID-19 and a case diagnosed with AIDS were listed separately, followed by 18 questions evaluating participants' personal and perceived stigma toward the hypothetical case. Participants were asked to choose their own answers from "strongly agree," "agree," "uncertain," "disagree," and "strongly disagree." The vignettes and stigma-related questions were as follows.

Vignette of COVID-19: "Li Ming (pseudonym) has been living in Wuhan. After the outbreak of COVID-19, he consciously isolated himself at home and wore a mask when he went out occasionally. Li Ming recently had a fever, cough and other symptoms. He was diagnosed with new coronavirus pneumonia and has been hospitalized. Li Ming did not know he was infected with the virus until he has been diagnosed."

Vignette of AIDS: "Zhang Yi (pseudonym) has been living in Wuhan. After the outbreak of the COVID-19, he consciously isolated himself at home and wore a mask when he went out occasionally. Zhang Yi recently had a fever, fatigue and other symptoms. He was diagnosed with AIDS and has been hospitalized. Zhang Yi did not know he was infected with HIV until he has been diagnosed."

Public's personal stigma attitudes were measured by the following nine questions: (1) If I were him, I would prefer to keep people from knowing about my situation; (2) I'm not willing to provide home service (such as delivery) for him or visit his home; (3) I think that he was affected by the disease because of his carelessness; (4) I think that his situation will cause problems to his family; (5) I think that his situation will have an adverse effect on others; (6) I will look down on him; (7) I try to avoid contact with him, especially physical contact; (8) I try to avoid contact with his family; and (9) I will look down on his family because of his situation.

Public's perceived stigma attitudes were measured by replacing "I think/will..." with "Most people think/will..." of the above nine questions.

We also investigated the usual source that participants used to get the COVID-19-related knowledge during the epidemic to estimate the role of each medium in spreading information.

\section{Ethical Considerations}

The study protocol was approved by the Ethics Committee of Second Xiangya Hospital, Central South University. Informed consents were listed on the first page of the questionnaire independently. Before answering questions, potential participants were asked to read informed consents carefully and determined whether they were willing to participate in this study. Those who click "yes" would obtain the whole questionnaire to complete, while others were displayed an end page of this study and appreciation.

\section{Statistical Analysis}

Frequency and percentage were used to describe demographic data while percentage frequencies and 95\% confidence interval (CI) were computed for stigma items. Categories of "strongly agree" and "agree" were merged into "agreement" for descriptions. A paired T-test was used to compare participants' stigmatizing attitudes between the two vignettes. All data
TABLE 1 | Demographic characteristics of participants $(N=13,994)$.

$n$

\begin{tabular}{|c|c|c|}
\hline \multicolumn{3}{|l|}{ Gender } \\
\hline Male & 7,757 & 55.4 \\
\hline Female & 6,237 & 44.6 \\
\hline Age & $30.4 \pm 9.6$ & \\
\hline \multicolumn{3}{|l|}{ Residence } \\
\hline Countryside & 4,765 & 34.1 \\
\hline City & 9,229 & 65.9 \\
\hline \multicolumn{3}{|l|}{ Residence during the epidemic } \\
\hline Hubei province & 1,864 & 13.3 \\
\hline Other province in China except Hubei & 12,017 & 85.9 \\
\hline Overseas & 113 & 0.8 \\
\hline \multicolumn{3}{|l|}{ Education (years) } \\
\hline$\leq 9$ & 901 & 6.4 \\
\hline$\leq 12$ & 5,352 & 38.3 \\
\hline$\leq 16$ & 6,273 & 44.8 \\
\hline$>16$ & 1,468 & 10.5 \\
\hline \multicolumn{3}{|l|}{ Marriage } \\
\hline Single & 5,968 & 42.6 \\
\hline Married & 7,423 & 53.1 \\
\hline Others (divorced/widowed) & 603 & 4.3 \\
\hline \multicolumn{3}{|l|}{ Income per year (thousand) } \\
\hline$\leq 50$ & 5,815 & 41.6 \\
\hline $60-100$ & 5,256 & 37.6 \\
\hline $110-190$ & 2,091 & 14.9 \\
\hline$\geq 200$ & 832 & 5.9 \\
\hline \multicolumn{3}{|l|}{ Occupation } \\
\hline Clinical staff & 1,790 & 12.8 \\
\hline Civil servant & 964 & 6.9 \\
\hline Employees & 4,517 & 32.3 \\
\hline Medical students & 1,017 & 7.3 \\
\hline Non-medical students & 1,783 & 12.7 \\
\hline Self-employed & 2,999 & 21.4 \\
\hline Others & 924 & 6.6 \\
\hline
\end{tabular}

analyses were conducted in SPSS 25.0, and $p<0.05$ was considered as statistically significant.

\section{RESULTS}

\section{Demographic Information}

In total, 19,355 questionnaires were collected and 5,341 were excluded after manual review. The screening principles were as follows: (1) $<2$ s to finish each item, (2) $\geq 2$ questionnaires from the same IP (only the first one was retained), (3) obvious errors, e.g., a 17-year-old person chooses "married" in the marriage item. Finally, 13,994 participants (55.4\% male) were included with the efficiency of $72.3 \%$. The average age was $(30.44 \pm 9.63)(x \pm s)$; $65.9 \%$ of the participants were from city. Over $54.3 \%$ participants were with the educated year longer than 12 years, and $13.3 \%$ were residents in Wuhan province during the epidemic. More demographic details are seen in Table $\mathbf{1}$. 


\section{Personal Stigma Toward COVID-19 and AIDS}

Participants' own attitudes toward COVID-19 and AIDS are presented in Table 2. Participants were most likely to agree to avoid contact either with people diagnosed with COVID-19 or with their family members, as $74.3 \%$ participants strongly agreed or agreed to avoid contact with people diagnosed with COVID-19 and 70.4\% strongly agreed or agreed to avoid contact with their family, while 59.0 and $47.9 \%$ participants tended to avoid contact with individuals diagnosed with AIDS and their families. Participants' agreements with the above two statements between COVID-19 and AIDS were significantly different. The third highest agreed statement toward COVID-19 was "I think his situation will cause problems to his family" (59.6\%), while $56.9 \%$ endorsed with the statement toward AIDS. There was also a high proportion of participants that thought that sufferers would have an adverse effect on others (55.6\% for COVID19 and $47.0 \%$ for AIDS). Endorsement with unwillingness to provide home service (such as delivery) or visit his home was 39.5\% for COVID-19 and 35.1\% for AIDS patients. Participants' agreement with keeping people from knowing their situation was $21.2 \%$ for COVID-19 and $38.4 \%$ for AIDS. Belief that suffering from COVID-19 or AIDS was patients' own fault was 23.0\% for COVID-19 and 39.3\% for AIDS. Agreement with the statement that they would look down upon the individuals with disease was $11.6 \%$ for COVID-19 and $17.8 \%$ for AIDS. Even $14.5 \%$ participants for COVID-19 and $17.8 \%$ for AIDS agreed that they would look down on patients' family because of the patients' situation. Participants' agreements with all of the above statements about their own attitudes between COVID-19 and AIDS were statistically significant $(p<0.001)$.

\section{Perceived Stigma Toward COVID-19 and AIDS}

Participants' agreements with statements about public attitudes are described in Table 3. Over 70\% participants tended to agree that others would try to avoid contact with COVID19 individuals (76.4\%) and their family (74.3\%), while the proportions of agreements in vignette of AIDS were $61.3 \%$ for individuals and $49.8 \%$ for their family. In the COVID-19 vignette, most participants agreed that the patients would cause problems to their family (64.0\%) and have side effects on others (59.2\%), while in the AIDS vignette, the percentages of agreement were 59.9 and $53.5 \%$, separately. Belief that most people were unwilling to provide home service (such as delivery) for the individual or visit his home was $51.6 \%$ for COVID-19 vignette, and $43.2 \%$ for AIDS vignette. More detailed information is described in Table 3. Participants' agreements with all of the above statements about most other people's attitudes between COVID-19 and AIDS were also statistically significant $(p<0.001)$.

\section{Usual Source to Get COVID-19-Related Knowledge}

Participants received COVID-19-related information was mainly from social media (91.3\%), newspaper or television $(77.1 \%)$, initiative network inquiring $(53.7 \%)$, and community publicity
(32.6\%) during the epidemic. Among that, over $60 \%$ of participants obtained most of the information from social media while $61.0 \%$ participants regarded the newspaper and television as the most reliable resource; details are listed in Table 4.

\section{DISCUSSION}

This study explored publics' stigmatizing attitudes toward COVID-19 during the epidemic and compared it with stigmatizing attitudes toward AIDS. The results showed that for COVID-19 beliefs about avoiding contact with individuals with COVID-19 and their families, individuals with COVID-19 would cause problems to or have an adverse effect on their families and others were much higher than other statements either in personal stigma or perceived stigma. For perceived stigma, unwillingness to provide home service or visit the home of individuals with COVID-19 was also among the highly agreed statements. Participants' highly agreed statements toward AIDS were similar with COVID-19 but had a slightly lower proportion, which were significantly different.

In the personal stigma dimension of COVID-19, people tend to keep distance with individuals diagnosed with COVID19, which is in accordance with the study by Sing Lee (29); they found that social distance might be related to severe acute respiratory syndrome (SARS) stigma. As close contact was one of the common transmission methods of COVID-19 (30), the Chinese government took several effective measures to stop people from contacting each other immediately after the outbreak of COVID-19, such as isolation, social distancing, community containment, and travel restriction (3). These policies effectively lower the transmission rate of COVID-19 but may produce stigmatization at the same time. Isolated individuals are more likely to suffer from stigmatization and social rejection (31). Some researchers claimed that stigma might negatively affect those with COVID-19 as well as their families, friends, caregivers, and communities (3). They might be experiencing "secondary" or "associative" stigma (32). There were several reports about COVID-19-related stigma to healthcare providers. In this study, numerous participants reported unwillingness to provide home service, which is similar to the existing views that the stigmatized group may experience stigmatizing behaviors such as isolation, refusal to provide service, and bullying (33). A relieving discovery was the low agreements about the statement of "I will look down on him or his family." This may be because COVID-19 spreads mainly through respiratory, and stigmatization against an individual is relatively lower than avoiding physical contact. It should be noted that in this study, $21.2 \%$ participants tended to keep it a secret if they were diagnosed with COVID-19, which can seriously expand the transmission and mislead the government into making wrong decisions about the epidemic and increase the difficulty of epidemic control.

In perceived stigma dimension, agreements with statements about COVID-19 were roughly similar to the statements described in personal stigma, but the proportion of each statement was slightly higher. That might be because people tend 
TABLE 2 | Percentage and 95\% Cl of participants who "agree" or "strongly agree" with statements about their own attitudes toward the person described in the vignette $(N=13,994)$.

\begin{tabular}{|c|c|c|c|c|c|}
\hline \multirow[t]{2}{*}{ Statements } & \multicolumn{2}{|c|}{ COVID-19 } & \multicolumn{2}{|c|}{ AIDS } & \multirow[t]{2}{*}{$p^{a}$} \\
\hline & $n$ & $\%$ & $n$ & $\%$ & \\
\hline If I were him, I would prefer to keep people from knowing about my situation & 2,968 & $\begin{array}{c}21.2 \\
(20.6-21.9)\end{array}$ & 5,368 & $\begin{array}{c}38.4 \\
(37.6-39.2)\end{array}$ & $<0.001$ \\
\hline I will look down on him & 1,627 & $\begin{array}{c}11.6 \\
(11.1-12.2)\end{array}$ & 2,485 & $\begin{array}{c}17.8 \\
(17.1-18.4)\end{array}$ & $<0.001$ \\
\hline I think his situation was caused by his own fault & 3,224 & $\begin{array}{c}23.0 \\
(22.3-23.7)\end{array}$ & 5,502 & $\begin{array}{c}39.3 \\
(38.5-40.1)\end{array}$ & $<0.001$ \\
\hline I think his situation will cause problems to his family & 8,340 & $\begin{array}{c}59.6 \\
(58.8-60.4)\end{array}$ & 7,962 & $\begin{array}{c}56.9 \\
(56.1-57.7)\end{array}$ & $<0.001$ \\
\hline I will look down on his family because of his situation & 2,035 & $\begin{array}{c}14.5 \\
(14.0-15.1)\end{array}$ & 2,403 & $\begin{array}{c}17.2 \\
(16.5-17.8)\end{array}$ & $<0.001$ \\
\hline I think his situation will have an adverse effect on others & 7,779 & $\begin{array}{c}55.6 \\
(54.8-56.4)\end{array}$ & 6,704 & $\begin{array}{c}47.0 \\
(46.2-47.8)\end{array}$ & $<0.001$ \\
\hline I will try to avoid contact with him, especially physical contact & 10,401 & $\begin{array}{c}74.3 \\
(73.6-75.0)\end{array}$ & 8,254 & $\begin{array}{c}59.0 \\
(58.2-59.8)\end{array}$ & $<0.001$ \\
\hline I will try to avoid contact with his family & 9,853 & $\begin{array}{c}70.4 \\
(69.7-71.2)\end{array}$ & 6,575 & $\begin{array}{c}47.9 \\
(47.1-48.7)\end{array}$ & $<0.001$ \\
\hline I am not willing to provide home service (such as delivery) for him or visit his home & 5,523 & $\begin{array}{c}39.5 \\
(38.7-40.3)\end{array}$ & 4,912 & $\begin{array}{c}35.1 \\
(34.3-35.9)\end{array}$ & $<0.001$ \\
\hline
\end{tabular}

a The $p$ value of paired-t test.

TABLE 3 | Percentage and 95\% Cl of participants who "agree" or "strongly agree" with statements about most others people's attitudes toward the person described in the vignette $(N=13,994)$.

\begin{tabular}{|c|c|c|c|c|c|}
\hline \multirow[t]{2}{*}{ Statements } & \multicolumn{2}{|c|}{ COVID-19 } & \multicolumn{2}{|c|}{ AIDS } & \multirow[t]{2}{*}{$p^{a}$} \\
\hline & $n$ & $\%$ & $n$ & $\%$ & \\
\hline Most people think he would prefer to keep people from knowing about his situation & 3,382 & $\begin{array}{c}24.2 \\
(23.4-24.9)\end{array}$ & 6,389 & $\begin{array}{c}45.7 \\
(44.8-46.5)\end{array}$ & $<0.001$ \\
\hline Most people will look down on him & 2,343 & $\begin{array}{c}16.7 \\
(16.1-17.4)\end{array}$ & 4,431 & $\begin{array}{c}31.7 \\
(30.9-32.4)\end{array}$ & $<0.001$ \\
\hline Most people think that his situation was caused by his own fault & 5,527 & $\begin{array}{c}39.5 \\
(38.7-40.3)\end{array}$ & 7,597 & $\begin{array}{c}54.3 \\
(53.5-55.1)\end{array}$ & $<0.001$ \\
\hline Most people think that his situation will cause problems to his family & 8,951 & $\begin{array}{c}64.0 \\
(63.2-64.8)\end{array}$ & 8,379 & $\begin{array}{c}59.9 \\
(59.1-60.7)\end{array}$ & $<0.001$ \\
\hline Most people will look down on his family because of his situation & 2,608 & $\begin{array}{c}18.6 \\
(18.0-19.3)\end{array}$ & 3,442 & $\begin{array}{c}24.6 \\
(23.9-25.3)\end{array}$ & $<0.001$ \\
\hline Most people think that his situation will have an adverse effect on others & 8,288 & $\begin{array}{c}59.2 \\
(58.4-60.0)\end{array}$ & 7,388 & $\begin{array}{c}53.5 \\
(52.7-54.3)\end{array}$ & $<0.001$ \\
\hline Most people try to avoid contact with him, especially physical contact & 10,688 & $\begin{array}{c}76.4 \\
(75.7-77.1)\end{array}$ & 8,579 & $\begin{array}{c}61.3 \\
(60.5-62.1)\end{array}$ & $<0.001$ \\
\hline Most people try to avoid contact with his family & 10,399 & $\begin{array}{c}74.3 \\
(73.6-75.0)\end{array}$ & 6,976 & $\begin{array}{c}49.8 \\
(49.0-50.7)\end{array}$ & $<0.001$ \\
\hline Most people aren't willing to provide home service (such as delivery) for him or visit his home & 7,224 & $\begin{array}{c}51.6 \\
(50.8-52.5)\end{array}$ & 6,050 & $\begin{array}{c}43.2 \\
(42.4-44.1)\end{array}$ & $<0.001$ \\
\hline
\end{tabular}

a The $p$ value of paired-t test.

TABLE 4 | Usual source that participants got COVID-19 related knowledge during the epidemic ( $n$, \%).

\begin{tabular}{|c|c|c|c|c|}
\hline & Newspapers/TV & Social media & Initiative network inquiring & Community publicity \\
\hline Channels to get epidemic information & $10,786(77.1)$ & $12,777(91.3)$ & $7,514(53.7)$ & $4,556(32.6)$ \\
\hline Channel to obtain most of the information & $3,169(22.6)$ & $8,441(60.3)$ & $1,860(13.3)$ & $524(3.7)$ \\
\hline The most reliable channel & $8,535(61.0)$ & 3,685 (26.3) & $1,185(8.5)$ & $589(4.2)$ \\
\hline
\end{tabular}


to answer the questions in an acceptable way to cater to public requirements (34).

AIDS stigma has been investigated by many scholars. In this survey, we found a number of similarities and differences between AIDS and COVID-19 stigma. A large proportion of participants were inclined to agree with avoidance of patients and their surrounding people and hold the opinion that patients would encumber others. This might be due to the similarity of infectivity and the psychological perspective that the negative emotions aroused by the two diseases generate similar patterns of stigmatization (35). Participants were more likely to keep it a secret if they suffered from AIDS compared with COVID19 for both personal and perceived stigma. Policy and moral condemnation may contribute to this difference. The Chinese government has already made some punishment policies to reduce the incidence of concealment and omission during the pandemic of COVID-19. Ways of transmission are quite different between these two diseases-primarily sexual and blood-to-blood for AIDS and primarily droplet transmission for COVID-19 (3). Hence, AIDS is usually conceptually linked to morality and equated with sexual promiscuity, homosexuality, drug abuse, and personal irresponsibility (36), while people with COVID-19 are less morally condemned. A higher proportion of participants thought that individuals with AIDS were more likely to be responsible for their situation and be looked down upon, but they may cause less problem to others compared with people with COVID-19. This might also relate to the different transmission methods of the two diseases and may indicate that stigma of COVID-19 had less moral link but more public panic.

Public response is closely related to the information they get and media report. Media report can powerfully influence public attitudes. Social media and newspapers/TV are the main usual source for the public to get information about COVID19. Social media could affect people's attitudes of risk perception while legacy media could affect public perceptions of protective behaviors. When the COVID-19 crisis was reported on TV or social media, some information might be misunderstood. Misinformation and rumors may produce public anxiety and panic and lead to a series of related behaviors such as prohibiting medical workers from going back home for fear of being infected. These media platforms are supposed to enhance public awareness without increasing fear and panic (37). Hence, measures should be taken to ensure the correct dissemination of information and reduce rumors during and after the pandemic.

In the present era, increasing our ability to reduce the stigmatization associated with emerging infectious diseases is required in controlling such diseases. A variety of methods have been taken with the attempt to reduce stigmatization associated with AIDS, such as basic public education about AIDS, publicized symbolic acts by public leaders or famous people, media campaigns, and designation of December 1 as World AIDS Day. These efforts have achieved some success (38). Our study showed many similarities between COVID-19related stigma and AIDS-related stigma; therefore, we could use the anti-AIDS-related stigma approaches to reduce COVID-19 stigma. Anti-stigma approaches toward mental disorders could also be considered. A pilot study on an anti-stigma course toward mental disorders, which consisted of three components, namely, social contact, role-playing, and critical reflection strategies, showed that participants' stigma attitudes were significantly reduced after the 18-week anti-stigma course (39). Another study examining the potential impact of an anti-stigma intervention on help-seeking attitudes, which included education about depression, information about help-seeking, and contact with a person with lived experience, showed improvements in help-seeking attitudes (40). Our data indicate that providing accurate COVID-19-related information through social media and newspapers/TV may be effective as these are the main sources they used to get COVID-19-related information. Public education may be another useful approach, and the abovementioned participants' highly agreed statements should be taken into consideration.

To our knowledge, this is the first study to compare COVID19 related stigma with AIDS related stigma. This survey has some limitations that need to be noticed. Firstly, convenience sampling method was used to collect data from the public by anonymous internet questionnaires, which might be the major limitation. Compared with random sampling method, convenience sampling method might easily lead to sampling error and bias, so that our respondents cannot represent well the population level. The sampling error may lead to inaccuracy conclusions. However, we tried to get as large a sample size as we can and be more cautious with our conclusions in order to avoid inaccuracy conclusions. Secondly, this was a cross-sectional study conducted during the pandemic, which can only reflect participants' attitude toward COVID-19 during the outbreak in China. Public's attitudes toward COVID-19 may change as we know more about this disease; we now are conducting a followup study to further investigate it. Thirdly, COVID-19 and AIDS are both infectious diseases but differ in transmission. There is no definite answer to whether the stigmatizations between these two diseases are completely comparable. A previous study has compared Chinese health professionals' attitudes toward patients with AIDS vs. patients with hepatitis B and found that health professionals had negative biases against AIDS patients and less willingness to interact with AIDS patients compared with hepatitis B patients (41), which indicates that stigmatizing attitudes toward COVID-19 and AIDS may be comparable to some extent. Logie also pointed out that we can use the experience of studying AIDS-related stigma and the approaches used in order to explore COVID-19-related stigma (26). Fourthly, we did not compare publics' stigma toward COVID-19 with stigma against non-communicable diseases such as mental disorders in this study. More efforts will be made to the comparison mentioned above in our future study. Another limitation is that the scale we used was adopted from the Explanatory Model Interview Catalog-Community Stigma Scale, which may not evaluate all aspects of COVID-19-related stigma. Hence, we just illustrate COVID-19-related stigma by describing the proportion of agreement with statements of the listed stigma-related items. Further non-convenience sampling and longitudinal study should be done to investigate more aspects of COVID-19-related stigma. 


\section{CONCLUSIONS}

Several similarities and differences in people's attitude toward COVID-19 and AIDS were found in this cross-sectional study. Avoidance, blame, and secondary discrimination to diagnosed persons and their surrounding persons were the main representations of stigma. Stigma of COVID-19 had less moral link but more public panic. Social media, television, and newspapers played a cardinal role in dissemination during the pandemic. Experience from AIDS-related stigma reduction and prevention can be applied to reduce COVID-19-related stigma. Social media, television, and newspapers should be made the best use, and the abovementioned highly agreed statements should be taken into consideration in further anti-stigma campaigns.

\section{DATA AVAILABILITY STATEMENT}

The raw data supporting the conclusions of this article will be made available by the authors, without undue reservation.

\section{ETHICS STATEMENT}

The study protocol was approved by the Ethics Committee of Second Xiangya Hospital, Central South University. Informed consents were listed on the first page of the questionnaire independently. Before answering questions, potential

\section{REFERENCES}

1. Chen N, Zhou M, Dong X, Qu J, Gong F, Han Y. Epidemiological and clinical characteristics of 99 cases of 2019 novel coronavirus pneumonia in Wuhan, China: a descriptive study. Lancet. (2020) 395:507-13. doi: 10.1016/S0140-6736(20)30211-7

2. Wu Z. McGoogan JM. Characteristics of and important lessons from the coronavirus disease 2019 (COVID-19) outbreak in China: summary of a report of 72314 cases from the chinese center for disease control and prevention. JAMA. (2020) 323:1239-42. doi: 10.1001/jama.2020. 2648

3. Bruns DP, Kraguljac NV, Bruns TR. COVID-19: facts, cultural considerations, and risk of stigmatization. J Transcult Nurs. (2020) 31:326-32. doi: 10.1177/1043659620917724

4. Pan XF, Chen DX, Xia Y, Wu XW, Li TS, Ou XT, et al. Asymptomatic cases in a family cluster with SARS-CoV-2 infection. Lancet Infect Dis. (2020) 20:410-1. doi: 10.1016/S1473-3099(20)30114-6

5. Lai CC, Shih TP, Ko WC, Tang HJ, Hsueh PR. Severe acute respiratory syndrome coronavirus 2 (SARS-CoV-2) and coronavirus disease-2019 (COVID-19): the epidemic and the challenges. Int J Antimicrob Agents. (2020) 55:105924. doi: 10.1016/j.ijantimicag.2020.105924

6. Sanche S, Lin YT, Xu C, Romero-Severson E, Hengartner N, $\mathrm{Ke}$ R. High contagiousness and rapid spread of severe acute respiratory syndrome coronavirus 2. Emerg Infect Dis. (2020) 26:1470-7. doi: 10.3201/eid2607.200282

7. World Health Organization. Coronavirus Disease (COVID-19) Pandemic. (2020). Available online at: https://www.who.int/emergencies/diseases/ novelcoronavirus-2019 (accessed March 12, 2020).

8. Polack FP, Thomas SJ, Kitchin N, Absalon J, Gurtman A, Lockhart S. Safety and efficacy of the BNT162b2 mRNA COVID-19 vaccine. $N$ Engl J Med. (2020) 383:2603-15. doi: 10.1056/NEJMoa2034577

9. Lopez Bernal J, Andrews N, Gower C, Gallagher E, Simmons R, Thelwall S. Effectiveness of COVID-19 vaccines against the B.1.617.2 (Delta) participants were asked to read informed consents carefully and determined whether they were willing to participate in this study. Those who click yes would obtain the whole questionnaire to complete while others were displayed an end page of this study and appreciation.

\section{AUTHOR CONTRIBUTIONS}

This study was conceptualized by TL, SC, YaL, and XW. The database was organized by YZ, YiW, YM, and YuL. Data analysis was done by ML and YuW. The manuscript with inputs was drafted by ML and YH. Reviewed by TL, SC, and JL. All authors read and approved the final manuscript.

\section{FUNDING}

This study was supported by the National Key R\&D Program of China (2017YFC1310400) and the Natural Science Foundation of Hunan Province (2020JJ4795).

\section{SUPPLEMENTARY MATERIAL}

The Supplementary Material for this article can be found online at: https://www.frontiersin.org/articles/10.3389/fpsyt. 2021.782501/full\#supplementary-material variant. N Engl J Med. (2021) 385:585-94. doi: 10.1056/NEJMoa210 8891

10. Laith J. Abu-Raddad, Butt A A. Effectiveness of the BNT162b2 COVID19 vaccine against the B117 and B1351 variants. N Engl J Med. (2021) 385:187-9. doi: 10.1056/NEJMc2104974

11. Goffman E. Stigma: Notes on the Management of Spoiled IDENTITY. Englewood Cliffs, NJ: Prentice-Hall, Inc. (1963).

12. WHO. Mental Health: New Understanding, New Hope. The World Health Report. Geneva: World Health Organization (2001).

13. Werner S. Public stigma and the perception of rights: differences between intellectual and physical disabilities. Res Dev Disabil. (2015) 38:26271. doi: 10.1016/j.ridd.2014.12.030

14. Jackson-Best FE. Stigma and intersectionality: a systematic review of systematic reviews across HIV/AIDS, mental illness, and physical disability. BMC Public Health. (2018) 18:919. doi: 10.1186/s12889-018-5861-3

15. Herek GM, Capitanio JP, Widaman KF. Stigma, social risk, and health policy: public attitudes toward HIV surveillance policies and the social construction of illness. Health Psychol. (2003) 22:533-40. doi: 10.1037/0278-6133.22.5.533

16. Anderson RM, Heesterbeek H, Klinkenberg D, Hollingsworth TD. How will country-based mitigation measures influence the course of the COVID-19 epidemic? Lancet. (2020) 95:931-4. doi: 10.1016/S0140-6736(20)30567-5

17. Zheng Y, Goh E, Wen J. The effects of misleading media reports about COVID-19 on Chinese tourists' mental health: a perspective article. Anatolia. (2020) 31:337-40. doi: 10.1080/13032917.2020.1747208

18. Xu T. Refuse Malicious "Labeling" and Resist Disease Stigmatization[N]. Health News, 2020-03-27(005) (2020).

19. Bagcchi S. Stigma during the COVID-19 pandemic. Lancet Infect Dis. (2020) 20:782. doi: 10.1016/S1473-3099(20)30498-9

20. Li W, Yang Y, Ng CH, Zhang L, Zhang Q, Cheung T, et al. Global imperative to combat stigma associated with the coronavirus disease 2019 pandemic. Psychol Med. (2021) 51:1957-8. doi: 10.1017/S0033291720001993

21. World Health Organization. 10 Facts on HIV/AIDS. (2018). Available online at: http://www.who.int/features/factfiles/ hiv/en/ (accessed May 10, 2018). 
22. Wohl AR, Galvan FH, Carlos JA, Myers HF, Garland W, Witt MD. A comparison of MSM stigma, HIV stigma and depression in HIV-positive Latino and African American men who have sex with men (MSM). AIDS Behav. (2013) 17:1454-64. doi: 10.1007/s10461-012-0385-9

23. Stangl AL, Lloyd JK, Brady LM, Holland CE, Baral S. A systematic review of interventions to reduce HIV-related stigma and discrimination from 2002 to 2013: how far have we come? J Int AIDS Soc. (2013) 16(3 Suppl. 2):18734. doi: 10.7448/IAS.16.3.18734

24. Turan JM, Nyblade L. HIV-related stigma as a barrier to achievement of global PMTCT and maternal health goals: a review of the evidence. AIDS Behav. (2013) 17:2528-39. doi: 10.1007/s10461-013-0446-8

25. Stangl AL, Earnshaw VA, Logie CH, Brakel WV, Simbayi LC, Barre I. The Health Stigma and Discrimination Framework: a global, crosscutting framework to inform research, intervention development, and policy on health-related stigmas. BMC Med. (2019) 17:31. doi: 10.1186/s12916-019-1271-3

26. Logie $\mathrm{CH}$. Lessons learned from HIV can inform our approach to COVID-19 stigma. J Int AIDS Soc. (2020) 23:e25504. doi: 10.1002/jia2.25504

27. Weiss MG, Doongaji DR, Siddhartha S, Wypij D, Pathare S, Bhatawdekar M. The Explanatory Model Interview Catalogue (EMIC). Contribution to cross-cultural research methods from a study of leprosy and mental health. Br J Psychiatry. (1992) 160:819-30. doi: 10.1192/bjp.160.6.819

28. Griffiths KM, Christensen H, Jorm AF, Evans K, Groves C. Effect of webbased depression literacy and cognitive-behavioural therapy interventions on stigmatizing attitudes to depression: randomised controlled trial. $\mathrm{Br} \mathrm{J}$ Psychiatry. (2004) 185:342-9. doi: 10.1192/bjp.185.4.342

29. Lee S, Chan LY, Chau AM, Kwok KP, Kleinman A. The experience of SARS-related stigma at Amoy Gardens. Soc Sci Med. (2005) 61:203846. doi: 10.1016/j.socscimed.2005.04.010

30. “Coronavirus Disease 2019". Centers for Disease Control and Prevention. Available online at: https://www.cdc.gov/coronavirus/2019-ncov/about/ transmission.html?CDC_AA_refVal=https\%3A\%2F\%2Fwww.cdc.gov\%2F coronavirus\%2Fabout\%2Ftransmission.html (accessed 11 February 2020).

31. Brooks SK, Webster RK, Smith LE, Woodland L, Wessely S, Greenberg N. The psychological impact of quarantine and how to reduce it: rapid review of the evidence. Lancet. (2020) 395:912-20. doi: 10.1016/S0140-6736(20)30460-8

32. Ransing R, Ramalho R, Filippis RD, Ojeahere MI, Karaliuniene R, Orsolini L. Infectious disease outbreak related stigma and discrimination during the COVID-19 pandemic: drivers, facilitators, manifestations, and outcomes across the world. Brain Behav Immun. (2020) 89:5558. doi: 10.1016/j.bbi.2020.07.033

33. Turner-Musa J, Ajayi O, Kemp L. Examining social determinants of health, stigma, and COVID-19 disparities. Healthcare. (2020) 8:168. doi: $10.3390 /$ healthcare 8020168
34. Wu Q, Luo X, Chen S, Qi C, Yang WFZ, Liao YH, et al. Stigmatizing attitudes towards mental disorders among non-mental health professionals in six general hospitals in hunan province. Front Psychiatry. (2019) 10:946. doi: 10.3389/fpsyt.2019.00946

35. Des Jarlais DC, Galea S, Tracy M, Tross S, Vlahov D. Stigmatization of newly emerging infectious diseases: AIDS and SARS. Am J Public Health. (2006) 96:561-7. doi: 10.2105/AJPH.2004.054742

36. Wight RG, Aneshensel CS, Murphy DA, Miller-Martinez D, Beals KPP. Perceived HIV stigma in AIDS caregiving dyads. Soc Sci Med. (2006) 62:44456. doi: 10.1016/j.socscimed.2005.06.004

37. Abdelhafiz AS, Alorabi M. Social Stigma: The hidden threat of COVID-19. Front Public Health. (2020) 8:429. doi: 10.3389/fpubh.2020.00429

38. Deacon H. Towards a sustainable theory of health-related stigma: lessons from the HIV/AIDS literature. J Community Appl Soc Psychol. (2006) 16:41825. doi: $10.1002 /$ casp. 900

39. Ma HI, Hsieh CE. An anti-stigma course for occupational therapy students in taiwan: development and pilot testing. Int J Environ Res Public Health. (2020) 17:5599. doi: 10.3390/ijerph17155599

40. Shahwan S, Lau JH, Goh CMJ, Ong WJ, Tan GTH. The potential impact of an anti-stigma intervention on mental health helpseeking attitudes among university students. BMC Psychiatry. (2020) 20:562. doi: 10.1186/s12888-020-02960-y

41. Li L, Wu Z, Zhao Y, Lin C, Detels R, Wu S. Using case vignettes to measure HIV-related stigma among health professionals in China. Int J Epidemiol. (2007) 36:178-84. doi: 10.1093/ije/dyl256

Conflict of Interest: The authors declare that the research was conducted in the absence of any commercial or financial relationships that could be construed as a potential conflict of interest.

Publisher's Note: All claims expressed in this article are solely those of the authors and do not necessarily represent those of their affiliated organizations, or those of the publisher, the editors and the reviewers. Any product that may be evaluated in this article, or claim that may be made by its manufacturer, is not guaranteed or endorsed by the publisher.

Copyright (c) 2021 Li, Long, Wang, Liao, Liu, Hao, Wu, Zhou, Wang, Wang, Wang, Ma, Chen and Liu. This is an open-access article distributed under the terms of the Creative Commons Attribution License (CC BY). The use, distribution or reproduction in other forums is permitted, provided the original author(s) and the copyright owner(s) are credited and that the original publication in this journal is cited, in accordance with accepted academic practice. No use, distribution or reproduction is permitted which does not comply with these terms. 